\title{
Arabic Writing, Spelling Errors and Methods of Treatment
}

\author{
Abeer Obaid Al-Shbail \\ Balqa Applied University, Jordan \\ Mostafa Awad Beni Diab \\ Balqa Applied University, Jordan
}

\begin{abstract}
This study attempts to investigate the most important difficulties and problems that resistant studying Arabic Writing, Especially dictation lesson, The researchers revises the pre-studies and literature to answer these important questions: - What are the most kinds of failing to master Arabic Writing, and the main factors that cause this failing? - What are the clear and common mistakes in studying Arabic Writing? What are the successful methods and strategies to teach Arabic Writing? The researcher revises the prestudies and literature, and produced wide information about: definitions, Kinds of Arabic Writing, factors of failing in studying Arabic Writing, especially dictation, the main principles to study Arabic language, Integrated Approach in studying Arabic Language, suggested program to answer failing and weakness in studying the Arabic language.
\end{abstract}

Index Terms-Arabic writing, spelling errors, methods of correctness

\section{INTRODUCTION}

Linguists and grammarians have worked hard since the end of the first Hijri century in the study of classical Arabic, given the association of this language with the Holy Quran, and they defined its features in terms of: sounds, formulas, structures, significance, syntax, and function of the word within this sentence.

Abd Al-Tawab (1999) claimed that the emergence of Arabic language with its various branches related to the study of the Holy Quran, so the Holy Quran was the focus of those studies, whether those related to the interpretation of the Holy Qur'an, eliciting its rulings, aspects of its miracles, or those that serve all these purposes by searching the significance, Formulas, syntax, and methods, even those related to spelling, or the art of Arabic calligraphy, all of these studies were carried out mainly to serve the Noble Qur'an, and to reveal aspects of its miracle, and thus facilitate the publication of the Islamic religion, and its legislation, thus motivating the interest of linguists in collecting Linguistic evidence and language restriction It is a religious motive, so that the scientific institutes mixed religious and linguistic knowledge in their curricula, and reached the maximum point that the teacher of the Arabic language is often reciter, interpreter, updated, or jurist, so Arabic has not become a universal language in the eyes of the orientalist (we generate it) except because of The Qur'an and Islam, and thus Arabic became a sacred language, and without the Qur'an it would not be Arabic.

Linguists believe that language is a system of sounds linked together in formats to express meanings stored in memory, and used in the process of communication between individuals and groups (Ahmad,1972), and language is the pot of thought, so language uses phonetic symbols to express this thought, and the concept of language is broad and not limited On spoken language, it also includes written (Mahmoud,1982), and spoken and written language are two complicated tools during which all life scenes and their experiences are transferred to memory verbally or in writing (Al-Mubarak,1981), A person acquires the ability to speak before writing; and given the importance of writing, Allah Almighty has sworn with its tools,: (Nun. By the pen and what they inscribe)(Al- Qalam: 1-2), Also, he said: O you who have believed, when you contract a debt for a specified term, write it down. And let a scribe write." (Al-Baqarah: 282). Writing has a profound impact on the lives of individuals, groups, and nations. The importance of writing in the advanced levels of education Language, to express feelings, ideas, record information (Al-Naqah,1985) and connect the past with the present, they are the memory of history, and the vessel of cultural achievement (Abu Odeh,1986).

\section{JUSTIFICATIONS OF THE STUDY}

A review of the theoretical literature on the problems of Arabic writing in general, and dictation in particular, found that there is an increasing interest among linguists and educators to seek effective solutions and methods in reducing the mistakes in writing in general and in spelling in particular.

- This study is in response to calls for educational development in most Arab countries, which calls for improving the language proficiency of our students. 
- This study draws attention to the importance of developing the Arabic language levels functionally, especially the written level (Abdo,1990).

- The researchers noted through their work in the education system the low level of students in the expression, the incidence of multiple spelling errors, the juxtaposition of the colloquial and the recommendations of the official, linguistics and educators to address this phenomenon, so this study contributes to this aspect.

\section{THE Study Problem}

The problem of the current study is that it tries to identify the difficulties and causes of weakness in the Arabic language at the level of spelling, and the detection of obstacles to mastery of spelling; as many of the official bodies and the popularity of Hala weakness of the level of students in Arabic, especially in spelling, Recommendations calling for the disclosure of these common errors, and explaining the reasons, and the development of methods and methods of treatment appropriate to reduce the spread in newspapers, magazines, books, and studies (Shehata, 1987).

In the opinion of the researchers, the Arabic language is indivisible, and its division into branches comes as a means of facilitating and facilitating the students studying. It is known that the study of all branches of Arabic is to reach the proper (oral and written) expression, so learn the grammar is to evaluate the tongue and pen of the melody in the Language and to learn spelling rules helps the integrity of the writing of linguistic error, as well as learning to read is to increase verbal wealth, ideas, images that serve expression.

\section{THE STUDY Questions}

The purpose of this study is to uncover the most important problems of Arabic writing in general, the reasons for spelling errors in particular, and the methods of treatment, specifically the answer to the following questions:

- What are the most important manifestations of weak spelling?

-What causes poor spelling?

-What are the common mistakes in spelling that many learners are faced with?

- What are the most effective methods and strategies for treating spelling errors?

\section{THE IMPORTANCE OF STUDYING}

This study contributes to the treatment of spelling weakness, emphasizes the importance of spelling in public and private life, and provides the curriculum makers with recommendations, results, and ideas that may help in planning to facilitate the teaching of Arabic in general and the spelling lesson in particular. And thus provide some solutions to address spelling error (Abu Shabab,2005).

\section{PREVIOUS STUdies}

Some researchers have conducted several studies on common spelling mistakes, which the researchers have learned, and the use of its content, analytical methodology, results, and recommendations. As follows:

1) The study of Al-Qaisi (1988), entitled: Common mistakes of students in the preparatory stage in spelling level in written expression.

The study aimed to identify the most common errors in written expression among middle school students. The study classified and analyzed such errors based on some of the strategies as the grammar system, the colloquial system and the phonetic system (the Accent), the system of use of punctuation. The study showed that the weak level of achievement has a significant impact in the incidence of spelling errors, and vice versa.

2) The study of al-Yaqoub (1990), entitled: Common mistakes among students of the governmental community colleges in Jordan, which aimed to reveal the common mistakes of the students of the government colleges in Jordan. The results showed that the weakness of the students in writing the hamzat qat " the hamzah which breaks, ceases or halts", and the hamzat mutatarifa" the hamzah comes at the end of the word, and is written according to the movement of the letter that came before it". The result revealed that the weakness of students in reading, the poor experience of lecturers, the lack of possession of advanced teaching methods, the lack of use of modern technology, and lack of guidance to students to their mistakes, and therefore lack of training to correct those mistakes.

3) El-Badawy's (1997) study entitled: An educational program based on the based on the integrative approach in dealing with some of the common spelling mistakes of the eighth grade, which aimed to reveal common spelling mistakes for eighth grade students in Jordan, and then built a therapeutic educational program based on the integrative approach in dealing with those spelling errors. The researcher develop an educational program that consists of defining the spelling activity that must be corrected, then the theoretical background for it, the common picture of that error, the goal of that spelling activity, then educational learning procedures to address that activity. The program contains ten activities, namely: stress, letters that has same pronunciation, substitution of the three letters of long vowels with the short diacritics, drawing of letters ta' marboota and ta' mabsoota, and al'alf allayna alqayima and almaqsura, the letters that pronounce and not written, and 'alf altafriq, drawing of hamzat alwasl and qaț', and drawing hamzat qaț'almutawasitati and hamzat qaț'almutatarifa. 
4) The study of Abu Shabab (2005), entitled: The effectiveness of the linguistic mental processes of dictation and educational dictation in the achievement and development of creative thought for the students of the basic stage of UNRWA in Jordan.

The study aimed to reveal the effectiveness of the linguistic mental processes of dictatorial and educational dictation in achievement and the development of creative thinking for students of the basic stage of the UNRWA in Jordan. The results showed that there are significant differences in spelling achievement attributed to mental language processes of dictation (proactive, educational, and ordinary) in favor of a group Impulsive dictation, and the existence of significant differences in creative thinking in its three areas (fluency, flexibility, and originality) due to the linguistic mental processes of dictatorial, educational, and habitual dictation in favor of the group of imperial dictation.

5) A study of Barakat (2009), entitled: Weakness in writing among the students of basic education in Jordan: its diagnosis and treatment.

Such research aimed to reveals the real causes of poor writing in the Arabic language for fourth, seventh, and tenth grade students from the viewpoint of students, teachers, and educational supervisors in Oman schools, and to build and evaluate a therapeutic model. The results showed that what is difficult for students is changing the image of the letter by changing its position, adjusting the letters, connecting and separating the letters.

Through a review of these studies, the researchers find a noticeable interest in the phenomenon of weakness in spelling at all levels of education, and that these spelling errors are common to all students, but it decreases as the student goes to higher levels, also the previous studies mentioned that there are several factors that contributed to the existence of this phenomenon. The previous studies also attempted to suggest treatment programs and methods, including the use of an integrative approach in teaching spelling, caring for a teacher who is the cornerstone of successful teaching of spelling, and the rest of Arabic domains, in addition to providing material and moral incentives.

The researchers believe that the practice and training in reading, spelling, and providing the necessary criteria for spelling and functional writing, then alerting to these spelling errors, and limiting and monitoring them, and emphasizing them during the treatment of language texts, and specifying a certain percentage for the excellence student of this spelling writing, and not to amplify these errors In a way that discourages the trust, it can reduce the prevalence of this phenomenon, in addition to enhancing the role of parents, the media, and official attitudes in caring for formal language in the formal institutions.

\section{THEORETICAL LITERATURE}

\section{A. Dictation in Arabic}

Dictation: It is drawing Arabic words using a linear depiction of spoken voices, with symbols that allow the reader to re-pronounce them in their first form, according to established rules developed by linguists (Abu Sharifa and Abdul Qader,1990). Shehata (1984) argues that dictation drawing is a specific linguistic system, the subject of which words must be separated or joined, the letters that are increased, the letters that are deleted, and all kinds of hamzah, ha' altaanith, all kinds of ta', and replacements the letters of alshamsia and alqamaria (Shehata, 1984).

In the view of Marouf (1991), the spelling is: conversion the understandable audible sounds to written symbols (letters), provided that these letters are placed in their correct positions, to correct the pronunciation, and the appearance of the desired meaning and the sounds may be completely equal to the letters, as these letters maybe not sounded, and here the confusion occurs with the student, then fall spelling mistake, since each letter in Arabic has its sound, it does not change by changing its position in the word, so if the student can draw letters aware of their movements and controls, able to distinguish between the three almd letters and their subordinate movements, he can write any word, taking into account some difficult spelling rules that can be solved (Maarouf, 1991).

In brief, spelling is a drawing of agreed-upon Arabic sounds or symbols by linguists, according to exact rules that must be mastered to reach the desired proper learning, and that lack of mastery will result in a linguistic error that leads to an imbalance of meaning.

The link between spelling and the rest of the domains of the Arabic language is closely related because all domains of the language are integrated to achieve the purpose of the language, which is to enable the learner to use the language properly for understanding, so the importance of teaching proper spelling comes in various kinds of language activities, and from the aspects that should be linked dictation: expression, reading, culture, calligraphy, and good habits as the quality attention, listening, coordination, and organization (Ibrahim, 1976).

The dictation in Arabic is high subtle, and easier when compared to other languages, and Arabic spelling is governed by precise rules and regulations, as a result of the great efforts made by the first linguists (Hamouz, 1989), The researchers believe that, despite the scarcity of anomalies and the ease of learning the rules of dictation, some obstacles impede learning and teaching Arabic writing in general, and dictation in particular, including letters movements, its voices, the connection of the rules of spelling with grammar, the presence of exceptions, and the differences in the images of one letter with a difference Its position in the word, refrainment, methods and methods used in dictation teaching, hence this study attempt to treat weakness in the mastery of this basic language skill among our students in all levels of education.

\section{B. Phases of Spelling Instruction}


Correct spelling is an important and fundamental process in education, as it is a key element in increasing an individual's culture, a social necessity for transmitting and expressing ideas, and reflecting on the ideas of others. Dictation is associated with expression, which is one of the essential foundations of biblical expression. If grammatical and morphological rules have a place in the validity and beauty of biblical expression, dictation is a highly influential means in it, because spelling error distorts writing, and hinders the understanding of the sentence, what calls for reducing the writer's value (Khater, 1986), It also prevents a proper understanding of the meaning, refers to the writer's weakness, and damages the weak spelled learner in his working life, as it may be difficult for him to join a job, or complete his education (Shomali,1995).

Unfortunately, the common errors are often counted in common traditional methods, as the teacher can highlight the spelling errors of his students in the student's workbooks.

Knowledge of the rules of spelling and its rulings requires technical and performance movements, and some researchers have proposed six stages to master those rules and provisions, which are (Zayed, 2007):

1- Pre-Pronunciation: Drawing similar shapes to invalid letters.

2- The stage of the initial pronunciation: It begins with writing almost letter-like forms.

3- The stage of naming letters and its sounds.

4- Transitional dictation phase: most of the educated voices are complete.

5- The etymological dictation stage: The student is proficient in writing most of the sounds from the rules and rules of spelling.

6- Idiomatic dictation stage: the student becomes able to master letters, distinguish sounds, and practice spelling in accordance with sound spelling rules.

Thus, we find that the spelling lesson must take a way to color the linguistic activity within the framework of the integrative approach, so the training of students on spelling writing is focused on caring for three things: enabling the student to write spelling correctly, mastery of writing, and expressing his ideas clearly and precisely.

\section{Types of Spelling}

Abu Shabab (2005) states that there are three types of dictation, namely:

1- Educational dictation: It is a type of dictation in which the student is trained to write words similar to the one that will be dictated to him, so the student is trained to simulate the pattern orally and in writing with phonetic and written analysis, then he writes similar words in the test.

2- Explanatory dictation: It is a type of dictation in which the student writes the words and texts that are written in writing, and then writes the reason under which he wrote these words in that spelling way, i.e. probing his creative mental processes.

3- Ordinary (experimental) dictation: It is a type of dictation in which it focuses on testing and measurement, and not on training and education. In this type, the student writes the text after reading it and then is tested in writing that text.

The researchers believe that it is possible to add other types that achieve the goal of the spelling lesson, including: summarizing some texts, discovering spelling errors in other texts presented to students that include intended errors related to the spelling lesson, or frequent copies of students who suffer from weakness in spelling writing.

\section{Spelling Error}

The language of the ancient linguists called the linguistic error (melody), and promised it a defect that should not be lost. The linguistic development through the Islamic civilization renaissance was the creation of manuscripts that alert to these linguistic errors, including: Al-Kasa'i (189 AH), And the author (216 h), entitled: (What the Common Folk), Ibn Al-Skeit (244 h) entitled: (Reform of Logic)

It is noticeable that there is a gap between the theoretical thought in teaching Arabic language and the practical reality of teaching it in our schools now, and this gap is widening day by day. It is well known that there is a strong relationship between grammatical, morphological and spelling rules. For example, it is not permissible to say: "ra'ayt almuelim alty ealamani" because ("alty") is an attribute of the feminine, and not of the masculine teacher, and likewise the matter of the past triptych verb " nazal " says it " ainzl " not " anzl " which is a command from the quadruple past "anzla". The student cannot evaluate his expressive writing without knowing the rules of grammar and exchange, including:: 'alf altafriqi, al'alf alliyna alqayima and almaqsura, al'asma' almawsula, hamza almutwstta, hamza mutatarifa, writing the 'in sha' allh, writing the word of "miat" without " 'alf " letter, deuteronomy the words that finish by hamzah mutatarifa, deuteronomy the words that finish by hamzah 'aslia, or hamzah munqaliba, or Deuteronomy, hamzat qaț' and alwasl, ta' almarbuta and almabsuta, and the letters that are pronounced and not written, written and not pronounced, punctuation marks, the writing of a son and daughter, and writing Converging letters in the director and the adjective, especially the numbered and luxurious ones, and other common mistakes (Zayed, 2007).

\section{E. Arabic Writing Difficulties and Problems Associated with Dictation}

The Arabic writing system is confronted by many problems, especially in the spelling lesson. The difficulties and problems are summarized in the Arabic script. As follows: 
1- System shape: It is intended to put the diacritical marks on the letters, which are the " aldima, alfatha and alkisra", which are short sounds, and similar to the letters "almid", and here is the error occurs between the diacritical marks and similar of the "almid" letters, as well as Tnwen and silence and distress, the word (eilima) can be read on several kinds if not controlled diacritical marks. As a result, there are a few can do that.

2- The difference between the drawing of the word and its voice: especially in words that have letters pronounced and not written, such as: ( hadha, hadhhun, dhalik, lakun, 'uwliik, thu"), and some of the letters that written and not pronounced, such as: " 'alf altafriq in jahiduu, walam yuqatilu", there is no doubt that the matching between sound and drawing facilitates writing.

3- The correlation of the rules of spelling Grammar: the student must learn the rules of derivation, reasoning, substitution, the inflectional position, and the type of letter that he will write, such as: " al'alf allyna" if it is a third that is mean the orginal is " ya'" then will write" maqsura"as " hudaa", also if the orginal was "waw" will write " 'alf qayima", as: "nama and asaa", and nd if it is in excess of three then will write "ya' " as in "suria, dunya, yahya" and excluded from the names (Yahya). As for the verbs, a sketch is drawn, such as: " aietadaa, aistathnaa".

4- The Difficulty of Spelling Rules: Like the "hamaza almtwsta", and "almutatarifa", and its many forms that need training and practice (Ibrahim, 1976).

5- The Number of Exceptions: Especially the drawing of the " hamzat qat' ", and its forms and provisions, and the hamzah on the line in the middle of the word if " 'alf" came before it, such as: yatasa'al, nabu'at, the himazat almutawasita have many complicated rules, rarely mastered by adults, so how about the young, which is either original, or by interpretation, Which is either static or mobile, or static after moving, or moving after static, and for each specific rule, which hinders the setting of spelling for students (Al-Qaisi, 1988).

6- The Difference Between Linguists in The Drawing of Some Words Because of The Difference in Spelling Rules: The hamza almutawasita in the word: "masyuwlia, or maswuwlita, and yaqri'uwna, yuqriwuwna, or yaqra'una, all are the valid drawing (Abu Shabab,2007).

7- The Difference of Drawing The Character According to The Position of The Word in A Misspelled Word: The difference in drawing the letter according to its position in the word spelling: There are some of the letters that have one image such as "aldaal, althaal, alraa', alzaayi, alzaa', alwaw". There are letters that have two images as " alba'a, waltaa', walthaa' ". Also, there are letters that have three images as " kaf and mim", and there are letters that have four images: aleayn, alghayn, alha'. Not to mention the psychological impact of this confusion on the psychology of the learner.

8- Al- Iajam: Pointed letters, it is noted half the letter are Iajam, such as Dal and Thal, and that the number of points varies according to the letters dotted, and the status of the dots varies according to the letters, and this is a problem.

9- The Letters Arrived and Separated: Connecting and separating letters: Arabic writing is distinguished by connecting its letters together, which makes the contours of the letters lost in the word, not to mention that the writing system requires that some letters be arranged vertically, and the other horizontally, and therefore the student needs to know the position of each of the two letters adjacent to it, there are letters connected with Some of them: alba', Sinn, Noon, and ya', and others that do not connect: alra', Dal, Thal, and this is one of the difficulties in the spelling lesson (Shehata, 1992).

10- Expression: The Arabic word in Arabic language is changing the spelling of its end in the linguistic structure which are "rufea, nasb, jr, and jazm", the name of the Ma'arab take the kind of "rufea, nasb, jr", and the verb take the kind of "rufea, nasb, jazm ", and there is a diacritical marks, and another by showing the letter, or by deleted, not to mention the case of the word in the place of "rufea, nasb, jr, and jazm", and there may be a change in the middle letters in the word: like the present hollow and the incomplete, and in the intention of the deficient to rufea and jr for example, these factors constitute an obstacle for the student to not master the grammatical rules And morphology, which constitutes a difficulty in the spelling lesson, as confirmed by the results of the study Kaisi (1987).

11- Use of Short Voices: This confuses the student for not being able to distinguish between the three diacritical marks and the letters of the "almd" to which they relate, the use of letters that represent the shortness of the student has the difficulty in distinguishing between the diacritical marks and throughout, Extinguishing sounds are an important step in the development of Arabic writing (Al-Yaqub, 1990).

12- Different Spelling of The Quran Spelling of drawing Spelling: in several places, is the increase, or deletion, or the connection, or separation, and the extension and capture.

13- The Diversity of Punctuation Marks: compared to other languages, and the correlation of these marks with other Arabic branches that the student needs to master before the spelling lesson.

In the study of Ibrahim Al-Qaisi (1988) found that the common mistakes in the written expression, which is one of the difficulties of spelling and problems, the most important of which are:

1- The letters that are added or deleted by the term: (taeilamu) which is not correct, the correct one should be (taelamuu), (arujua) and the right thing is 'arju, ('an takunu) and the right thing is 'ana takunuu. (laakna) and the right lakuna, (bdhalika) and the right is bidhalika, (Khaled Ibn Al Walid) and The Righteous Khaled Bin Al Waleed. 
2- Wrong spelling by increasing the character on the word, or decrease the character, or replace the letter, or provide the characters right delay, such as: alladhi, the corrected one is aladhi, alsaghr walkabar the right one is alsaghir walkabiri, mutahanat the corrected one is aimtihanatin.

3- The mistakes of the long and short movements: 'alaf has long fatha, as well as the waw and the yaa and these errors aeifiat which is wrong and writing as eafiatun, also yantah which is wrong and writing as yantahi.

4- Ta' mrbwtta, almbswtta and ha': among these errors is jamaeat and righteousness jamaeatun, wabahi taenat and the righteous is wabih tienatun, tarbayt alhamam and the righteous is tarbiat.

5- Humazat alqte and alwsl, including: bisul and rightness is bialsuwal, 'iibda' and rightness is abda, biraasat and rightness is biriasat, bi'iintsar and rightness is biaintisarin, lanah and rightness is li'anah, aldifi and rightness is aldaf', shayy and rightness is shayi', tabati and rightness is tabatw, manlyum and rightness is min alyawm, wanatahat and rightness is waintahat.

6- The difference between alnuwn and altanwina: 'ahyanin and rightness is ahyanaan.

7- Replacing the letters: towards: fawaeidih and rightness is fawayiduhu, min makan 'iilaa makan and rightness is 'iilaa ‘murtabit and rightness is mrtbt.

8- Grammatical errors.

\section{9- From Colloquial Errors.}

10- Replace the letters hase same spelling, towards: the destruction of many warriors and the right to save, between his muscles and right his muscles, and the defenseless defending the Muslims and the right shadow, the Jews are hard and right and ravenous, Zalk man and the right is (thalika).

The researchers believe that one of the common mistakes that studies and literature did not refer to is to draw the severity over the weakened letter, especially the " ya' alnsb", because the severity has an effect in changing the meaning. i.e kitabi, and ktaby, the first humza is ya' almutaklim, but the second ya' is ya' alnsb.

Barakat (2009) finds that the difficulties faced by students are exaggerated, they exist in all languages, and that the Arabic characters are characterized by harmony, conciseness, beauty and shape in the building skill.

\section{F. Examples of Common Misspellings}

In view of the increased interest in dealing with common spelling mistakes, Fahd Zayed (2007) has identified a set of common spelling mistakes in which many students fall into a book of common mistakes without tabulation or analysis, which can be emphasized by educational planners, linguists, teachers, And students alike, and to increase the benefit will be classified by the researcher, namely:

- Do not differentiate between the taa' almarbutat and aha' of absent, as their words: Bilrafah and baneen: the right to bialrafaahi, miat the right is miah.

- Do not differentiate between the waw aljame' and waw aljamaeat which followed by 'alf altafriqi , as saying: alfawakata the right is alfawakih.

- Do not differentiate between al'alf alliyna alqayima and ya' almaqsura.

- Do not differentiate between the meaning.

- Not to differentiate between al'iibdal and al'iidghami.

- Lack of mastery of some spelling rules, towards: if he does what he wants: and the right to do what he wants, the establishment of God: and the right, In Shaa Allah.

Sabitani (1997) also identified a group of common spelling mistakes in which students can be placed in a special author without arrangement or analysis. In order to increase their usefulness, the researcher will classify them as follows:

- The rules of humaza almutatarifa written on the almad letter appropriate for the diacritical marks before the humaza.

- Do not differentiate between tethered and unscrupulous.

- No distinguish between ta' almarbuta and ha' aldamir.

- Do not distinguish between ta' almarbuta and almabsuta.

- No differentiate between the al'alf alliyna and Almqsoura.

- And the lack of mastery of the rules of the separation after the waw aljamaeat.

- Lack of mastery of grammatical rules.

- No rules of increase and deletion in some words.

- The lack of mastery of exchange rules.

- Errors in single, compound and round numbers.

\section{G. Treatment of Common Mistakes in Arabic Writing, Especially Spelling}

Many educators and linguists complain about the poor level of learners in the Arabic language at all scientific levels, which is a chronic problem, some of which may be due to the curriculum, and the other to grammatical terminology.

This is a great danger, as the classical language will fade, and we can not agree on any dialect in the Arab countries. Arabic has a special situation that differs from the rest of the languages of the world, and we are not with those who call for the use of colloquial, or intermarriage between it and Al-Fusha, and this is a great danger, as Al-Fusha will decay, and we cannot agree on any colloquial dialect in the Arab countries. The Arabic language originally originated to serve 
the Holy Qur'an And understand the provisions of Islam, and write down our huge Arab heritage, and it is not just a language for communication, it is a sacred language, and the Lord of Glory has guaranteed this Qur'an to us in that language. Most of it said: "We descended the remembrance and we have it for the keepers" Al-Hijr: 9 Arabic must stem from this premise, which is its connection to the Holy Quran and its service, and publication Islamic religion, the Arab heritage and authentic (Abdul Tawab, 1999).

It is noted that there is a dangerous feeling among our intellectuals that our beautiful classical language is a complicated language, difficult to learn, and many homosexuals, so the enemies of Islam seized this opportunity and called for the use of colloquialism, so as to distract Muslims from understanding their noble Qur'an, the teachings of their great religion, and the fact that this complexity that is described Arabic is present in all languages. Arabic is not an innovation among languages. The basic principle is to summarize these rules in a few pages, and to include them with the student in his study levels (Abdul Tawab, 1999).

The teacher of Arabic represents the solver in solving this problem, and therefore the greatest responsibility rests, as most of those enrolled in literary colleges are weak graduates, and they are forced into them, after the other faculties are blocked in their faces, and you are surprised that students of the Faculties of Science and Medicine see geniuses in Arabic, They say poetry, and they taste it, unlike students of the Faculties of Arts, so students of the College of Arts should be handpicked and lured with rewards.

It is a mistake for those who think that teaching grammar and focusing on it is language teaching, and this thinking is similar to who teaches presentations to create a poet, as all these methods are repeated by the student at an early age without awareness, then forget them, and the principle is that we train in speech or classical writing, then we evaluate it In this way, the student is familiarized with the structures of language and their meanings, memorizing and understanding, then measuring them, as the focus and encouragement to read literary texts, especially the Holy Qur'an, and the noble hadith have a profound impact on learning Arabic, and thus the scholar called Ibn Khaldoun when he said: He who seeks the Queen and intends to collect it will take himself by keeping their old words The current day is based on their methods from: the Qur'an, the hadith, the words of the predecessors, and the addresses of the stallions of the Arabs in their bravery and poems ... so that the most memorized words of the system and those strewn down the rank of those who lived among them ( Ibn Khaldun, 2006).

The control of texts has a profound impact on the proper understanding and pronunciation of the word, and the audiovisual media can play a role in disseminating Al-Fusha.

One of the most useful methods and methods used in this context to address the common mistakes in Arabic writing, especially spelling, is the comprehensive educational approach based on the complementary approach proposed by alBadawi (1997). It identifies some of the spelling errors that Arab children suffer, including: letter forms, and the convergence of their voices, and diacritical marks related to the letters of the almd, and this calls for specialists further analysis, training and treatment, and do not forget here the relationship between the validity of spelling and good comprehension, the quality of expression of meanings and reading. The proposed program includes a set of activities related to some spelling errors, in terms of: theoretical background, common image of spelling error, special purpose of activity, educational procedures, as follows:

- Activity 1: Stresses (marking the severity above the weakened letter)

Theoretical background: It means two similar letters, the first is consonant and the other is moving, they become one letter accentuated.

Common image of the spelling error: Not to put a stress on the weakened letter, such as: surr, shddad.

The special purpose of the activity: The student draws intensity over the weakened letter that is pronounced as two letters.

Educational procedures: The teacher clarifies the concept of weakness, gives examples, and trains the proper drawing of the weak.

- Activity 2: Converged letters in the output

Theoretical background: It means the almuraqaqa and almufkhama converged in the output and the characteristic: as siin and Sad, aldhaal, alzaa'i, aldaal, aldaadd.

Common image of misspelling: Character is incorrectly drawn due to audio, socialization, or other factors.

Special purpose of the activity: to enable students to draw sound according to the meaning of the word or pronunciation of the letter

Educational Procedures: The teacher reviews the intended characters, trains students, and addresses spelling errors

- Activity 3: Replace the letters of the almd with diacritical marks or vice versa

Theoretical Background: The letters of the three tenses are the 'alf, alwaw, ya, and they have diacritical marks similar to those in the pronunciation, which are the fatha same pronunciation with the 'alf, aldima same pronunciation with the alwaw, alkusra same pronunciation with the ya'.

Common misspelling: There are common misspellings due to the fact that the three diacritical marks are not separated by the corresponding pronouns in pronunciation.

Special purpose of the activity: To distinguish the student in the spelling between the diacritical marks and the similar tide 
Educational procedures: The teacher shows the difference between the letter of the almd and the diacritical marks, gives examples, how to draw the spelling of each, and trains students on it.

- Activity 4: Drawing the ta' almarbuta and ta' almabsuta

Theoretical background: The ta' almarbuta means the ta', which is the sign of the femininity of the singular noun, and the pronunciation of ta' in the connection and the end.

The common picture of the spelling error is the weakness of the students in drawing the forms of ta' and properly knotted.

Special purpose of the activity: To differentiate the students in the spelling between the tethered and strained

Educational Procedures: The teacher writes examples of the tethered and tethered lines, and asks the students to differentiate between them, reaching the rules of their proper drawing, then asking them to give examples, and more training.

- Activity 5: Soft Alif and Al maqsoura Alif in a name:

Theoretical Background: soft alif ones are those that come in the last word, preceded by Fath, which is either: a list that turns and waits in the present tense, and turn to a compartment written in the form of yaa, and a variance in the present, and a yaa in Muthanna.

The common image of the spelling error: the inability of students to draw a thousand list, which is spelled correctly spelling because they do not differentiate between them.

Special goal of the activity: to enable students to draw words that end in stand 'alif and others are properly compartmentalized

Educational procedures: The teacher sets a set of words ending with a thousand list and other names, actions and letters, and discuss the students, and come to the rules of drawing the correct spelling

Special goal of the activity: to enable students to draw words that end in a thousand list and others are properly compartmentalized

Educational procedures: The teacher sets a set of words ending with a thousand list and other names, actions and letters, and discuss the students, and come to the rules of drawing the correct spelling

\section{- Activity 6: The letters that say and do not write}

Theoretical Background: There are letters in Arabic that are pronounced at the time of reading and do not spell, which are exceptions. They are confined to some words, such as: hadha, hadhhu, lakuna, 'uwliika, dawud.

The common image of the spelling error: students are misled when drawing these words because of their lack of proficiency or memorization of these common words.

Special purpose of the activity: to master the student drawing the correct spelling of the words in which the words are pronounced and not written

Educational procedures: The teacher restricts those words, and trains students to draw the correct spelling.

\section{- Activity 7: A differentiate Alif}

Theoretical background: A thousand differentiation means those that are increased after the group waw in the last act connected to it, or the five acts that are fixed and broken.

The common picture of the spelling error: Do not draw a distinction properly.

Special purpose of the activity: Enabling students to draw 'alif differentiation after the group waw properly.

Educational Procedures: The teacher monitors some past actions related to the group, and the five actions that are scored and trained, and trains the students on them, and then recommends placing 'alif extra to differentiate them from the rest of the waw group.

- The eighth activity: humazat alwasl, hamzat qat'

The theoretical background: The humazat alwasl is 'alif written in the first word to reach the pronunciation of the static alphabet. It is pronounced at the beginning and is deleted at the junction.

Common image of the spelling error: The spelling error is often in the humazat alwasl and hamzat qat' drawing because of its many rules

Special purpose of the activity: Students should master the drawers of the humazat alwasl and hamzat qat' properly, and the difference between them.

Educational Procedures: The teacher sets a set of words that include the drawing of the humazat alwasl and hamzat qat', trains the students on their bases, and draws them with proper spelling, with reasoning.

- Activity 9: Drawing of the humazat alqat' almutawasita

Theoretical Background: The clasp is the one that is pronounced where it occurs in the name, the verb or the character. It is called cut because it cuts the letter before it from the letter after it, and draws either on a list.

Common image of the spelling error: inability to draw the middle Hamza on the appropriate tide character

Special purpose of the activity: Mastering the students to draw the medium-sized medallion spells properly.

Educational Procedures: The teacher sets out a group of words that are located in the middle of the hummus, and discusses with the students the proper drawing of the Hamza according to its rules.

- Activity 10: drawing the humazat alqat' almutatrefa 
Theoretical background: The clasp is the sign of where it occurs in the name, the verb, the letter, and wherever it occurs in the word, and it is called the alqat' because it cuts the letter before it from the letter after it, and draws either 'alf qayima, waw, ya', Or on the line according to their rules

Common image of the spelling error: inability to draw an Hamza almutatrefa on the appropriate almd letter.

Special purpose of the activity: to be proficient student drawing Hamza almutatrefa by spelling according to their rules.

Educational procedures: The teacher sets a set of words that fall humazat alqat', and discuss with the students the proper drawing of those Hamza according to their rules.

It is noted from this proposed program that it has absorbed many of the common spelling issues, identified them and analyzed them in four aspects: their theoretical background, the spelling error, the purpose of the activity and the procedural way of carrying out the activity. This method is undoubtedly appropriate and effective if done by teacher who is capable of his material, has good performance and execution, and a self-confident personality. Other common misspellings can be identified and treated in the same way.

\section{CONCLUSION}

The current study attempted to uncover the problems of Arabic writing, the reasons for spelling errors, and the methods of treatment. After reviewing the theoretical literature and related studies, the following conclusions can be drawn:

- Arabic: read, written sacred language, and a rite of the rites of Islam, approached by the practice of God Almighty; so must be mastery, and practice the four skills properly; because it is the language of the Holy Quran, which is immortal.

- Arabic is a language in which the meaning is influenced by the change of diacritical marks, or the spelling, which leads to falling into the linguistic melody, and thus change the meaning, and corrupt, and perhaps underestimated the perpetrator.

- There is a great interest by researchers and linguists in the Arabic language, in general, and the lesson of spelling in particular, and they have good efforts in trying to overcome obstacles to the people of Arabia, and their request;

- Many Arab students at all levels suffer from poor spelling, and some are due to many factors, including: membership, educational, social, and others due to the nature of the Arabic writing, and the multitude of rules.

- Failure in one of four language skills: reading, writing, speaking, and listening leads to failure in educational advancement, and perhaps in the individual's own life.

- The spelling lesson has a particular place in the language lesson, and is influenced by other levels of language: vocal, morphological, grammatical, semantic, and rhetorical, further complicating the proficiency of spelling.

- There are principles and educational foundations proposed to teach spelling rules can contribute to reduce the problems of spelling, so must be the implementers and implementers of educational curricula to take them, and benefit from that end.

- There are many attempts by a group of researchers and scholars to identify most of the spelling errors common in the Arabic writing, and classification, and determine the rules, and thus can contribute to the treatment of the phenomenon of serious language.

- The study presented a set of proposed activities, strategies and programs that proved to be effective, which can be utilized, and can contribute to the mastery of Arabic writing, the most important of which is the integrated approach in the teaching of Arabic language branches.

- The results of many researches and studies indicate the importance of the role of the teacher in the success of any language lesson, so it is necessary to focus on the role of the Arabic language teacher, and training, and enhance the role and reward: materially, morally.

\section{RECOMMENDATIONS}

The researchers recommend building and developing educational curricula and taking advantage of the results of educational studies related to the problems of Arabic writing, and the proposed programs and strategies that have proven successful. The researchers recommend the decision-makers in the Arab Ministries of Education to pay attention to preparing the teacher of the Arabic language: academically, professionally, and educationally, and to develop his capabilities so that the required change occurs in improving Arabic writing and getting rid of its problems. It also recommends that the teacher of the Arabic language, in particular, make a special effort to develop himself first, in terms of possessing the necessary linguistic competence and skilled technical performance, so that all of this is reflected on his students, as the Arabic teacher plays a thankful role in preserving the Islamic identity of students, Deepening affiliation with the nation's culture, its religious, historical and scientific heritage.

\section{REFERENCES}

[1] Abdo, D. (1990). Towards Teaching Functional Arabic, Amman, Jordan, Dar Carmel.

[2] Abdul Tawab, R. (1999). Chapters in Arabic jurisprudence, Cairo, Al-Khanji Library. 
[3] Abu Odeh, O. (1986). Tracking the Written Mistakes of the First Three Students in Amman Governorate, Unpublished Master Thesis, Amman, University of Jordan.

[4] Abu Shabab, A. (2005). The Effectiveness of the linguistic mental processes of dictation and educational dictation in the achievement and development of creative thinking for students of the basic stage of UNRWA in Jordan, unpublished doctoral thesis, Amman Arab University, Amman, Jordan.

[5] Abu Sharifa, A. (1990). Studies in Arabic Language, II, Dar Al-Fikr, Amman.

[6] Al-Qaisi, I. (1988). Common Mistakes in Preparatory Students at the Level of Written Expression, Unpublished Master Thesis, Yarmouk University, Irbid, Jordan.

[7] Al-Mubarak, M. (1981). Jurisprudence and Characteristics of Arabic, I7, Damascus, Dar al-Fikr.

[8] Al-Naqah, M. (1985). Arabic Education Program for Non-Arabic Muslims in Other Languages in the Light of Their Motivation, Umm Al-Qura University, Arabic Language Institute, Research and Curriculum Unit.

[9] Al-said, M. (1972). Foundations of Selection of Grammar Subjects for the Preparatory Stage, PhD Thesis, Ain Shams University, Cairo.

[10] Al-said, M. (1980). Curriculum Development Curriculum and Methods of Expression, Dar Al-Ma'aref, Cairo.

[11] Al-said, M. (1982). Methods of Teaching Arabic Language, Amman, Al Ittihad Press.

[12] Al-Yaqoub, N. (1990). Common Mistakes in the Students of Government Colleges in Jordan, Unpublished Master Thesis, Yarmouk University, Irbid, Jordan.

[13] Badawi, M. (1997). The impact of an educational program based on the integrated approach in the teaching of Arabic in the treatment of spelling mistakes common among the students of the eighth, unpublished Master thesis, Irbid, Yarmouk University, Jordan.

[14] Barakat, S, Mohammed A. (2009). Weak Writing in Basic Education Students in Jordan: Diagnosis and Treatment, Yarmouk University, unpublished $\mathrm{PhD}$ thesis, Irbid, Jordan.

[15] Dhafer, M, Hammadi, Y. (1984). Teaching in Arabic Language, Riyadh, Dar Al-Marikh.

[16] Hamouz, M. (1989). Spelling Errors Resulting from grammatical, morphological and phonetic dimensions in the Arabic conventional line among students in the first secondary grade in the Greater Amman Directorate, unpublished master thesis, University of Jordan, Amman, Jordan.

[17] Hawri, U. (1993). Arabic language skills in the first four grades, Yemen, Ministry of Education.

[18] Ibn Khaldoun, A. (2006). Introduction, Beirut, Modern Library.

[19] Ibrahim, A. (1978). Spelling and numbering in Arabic writing, Cairo, Dar Maarif.

[20] Ibrahim, A. (1976). Unification of Spelling in the Arab World, Conference of Arab Teachers' Union, Khartoum, Modern Printing House.

[21] Khater, M. (1986). Methods of teaching Arabic in the light of modern educational trends, 3, Cairo, Dar Al Ma'arif.

[22] Maarouf, N. (1991). Teaching spelling and teaching in the Arabic language, I 5, Lebanon, Dar al-Nafas.

[23] Muhammad, S. (1980). Teaching Arabic at the secondary level, Kuwait, Dar Al-Qalam.

[24] Murad, S. (2002). Integrative in Teaching Arabic Language, Irbid, Jordan, Dar Al-Amal.

[25] Samir, R. (1995). Arabic language curricula and methods of teaching, Yemen, Ministry of Education.

[26] Sbitani, Y. (1997). Common Mistakes, 1, Riyadh, Dar Tuwaiq.

[27] Shehata, H. (1978). Teaching Arabic Language between Theory and Practice, Cairo, The Egyptian Lebanese House.

[28] Shehata, H. (1984). Fundamentals of Spelling Education, Cairo, Arab Gulf Foundation.

[29] Shehata, H. (1992). Teaching Spelling in the Arab World: Founding, Evaluating and Developing it, Cairo, The Egyptian Lebanese Library.

[30] Shehata, H. (1987). Common Errors in Spelling for the Last Three Classes of Primary Stage: Diagnosis and Treatment, Unpublished Master Thesis, Ain Shams University, Cairo.

[31] Shumali, A. (1995). Weakness of students in dictation from the third to sixth grade, and methods of treatment, Journal of Humanities Studies, University of Science and Technology, Irbid, Jordan.

[32] Zayed, F. (2007). Common Mistakes: grammatical, grammatical, and spelling in students of the upper elementary grades, 1, Amman, Dar al-Yazuri.

[33] Zayed, F. (2007). Common Mistake between Public and Private, 1, Amman, Dar Al-Nafas.

\footnotetext{
Abeer Obaid Al-Shbail was born in Jordan -Irbid on Eighth -August -1978. She got her PhD degree in Applied Arabic linguistics from Yarmouk University/ Jordan by 2010. She is currently occupying an assistant professor position in Department of Arabic Language/Irbid University College/Balqa Applied University/ Jordan. She published a number of articles such as: Tolerance culture in children literature: a case study on Jordan, Journal of Language and Literature, 2013.
}

Mostafa Awad Beni Diab was born in Jordan -Irbid in April -1963. He got his PhD degree in Applied Arabic linguistics from Yarmouk University/ Jordan by 2002. He is currently occupying an associate professor position in Department of Arabic Language/Irbid University College/Balqa Applied University/ Jordan. He published a number of articles in Applied Arabic linguistics. 